\title{
Preparation and Characterization of Poly (3-hydroxy- butyrate-co-4-hydroxybutyrate)/Porous Cellulose Aerogel Biocomposites
}

\author{
Fen Yin, Xuejiao Zhang, Dongna Li, and Xiaojun Ma* \\ A green biocomposite of poly(3-hydroxybutyrate-co-4-hydroxybutyrate) \\ (P34HB) and cellulose aerogels was developed. Cellulose gel was \\ prepared from $\mathrm{NaOH} /$ urea aqueous solution, and subsequent \\ regenerating by $\mathrm{Na}_{2} \mathrm{SO}_{4}$ solution and freeze-drying resulted in porous \\ cellulose aerogels. The $\mathrm{P} 34 \mathrm{HB} /$ cellulose aerogel biocomposite was \\ fabricated by immersion of porous cellulose in a polymer solution and \\ hot-pressing. The morphology, crystallization, thermal, mechanical, and \\ barrier properties $\left(\mathrm{H}_{2} \mathrm{O}\right)$ of biocomposite were investigated. The cellulose \\ aerogels matrix exhibited a three-dimensional network structure with \\ porosity and a wide pore size distribution, contributing to the change of \\ the glass transition temperature and cold crystallization temperature of \\ biocomposites. Compared with cellulose aerogels, the tensile strength \\ and elongation at break of biocomposites were increased by as much as \\ $48 \%$ and $25.1 \%$, respectively. Moreover, biocomposites demonstrated \\ an increased contact angle and water vapor permeability coefficient \\ compared with the cellulose aerogel. The results revealed the potential \\ of $\mathrm{P} 34 \mathrm{HB} /$ cellulose aerogel biocomposites for practical application as \\ packaging materials.
}

Keywords: Cellulose aerogel; P34HB; Biocomposite; Mechanical properties

Contact information: College of Packaging \& Printing Engineering, Tianjin University of Science \& Technology, Tianjin 300222, China; *Corresponding author: mxj75@tust.edu.cn

\section{INTRODUCTION}

Faced with the gradual consumption of fossil fuel resources and the harmful effects of waste oil based plastics on the environment, it is necessary to develop novel, ecofriendly polymers (Wang et al. 2015; Du et al. 2018). Poly(3-hydroxybutyrate-co-4hydroxybutyrate) (P34HB) has gained popularity as a sustainably derived bioplastic due to its biocompatibility and biodegradability in medical devices and packaging materials (Seoane et al. 2015; Xu et al. 2017). P34HB exhibits a suitable melting point range and excellent properties, fulfilling different requirements via adjusting the 4HB monomer ratios (Che et al. 2018). However, its practical applications have been limited because of its poor crystallization, narrow thermal processing window, low mechanical properties, and high cost (Cai et al. 2016; Larsson et al. 2017).

Cellulose is the most abundant natural polymer material. It has the advantages of renewability, good biodegradability, and excellent biocompatibility. It is widely used in various fields because of its low price, good flexibility, and high mechanical strength (Chen et al. 2015; Guo et al. 2018). Compared with other aerogels (silica or fossil fuelbased aerogels), cellulose aerogels have the typical characteristics of high porosity, large surface area, and low density, but they also have high flexibility, biocompatibility, and 
biodegradability (Chen et al. 2015; Guo et al. 2017). Thus, cellulose aerogels are appropriate as green matrix materials. In addition to these advantages, cellulose aerogels show some unsatisfactory structural properties, i.e., weak mechanical strength, uneven structure, and brittle fracture, which limit their applications in many fields. To solve this problem, adding reinforced filler is an effective way to enhance the mechanical properties of aerogels (Bo et al. 2018).

Several studies regarding the synthesis of cellulose composites with the most common PHAs members, PHB, and PHBV have been reported (Chiulan et al. 2016; Cherpinski et al. 2018). However, there has been a lack of reports on the synthesis of cellulose aerogel composites with PHAs. In this study, A novel green biocomposite from P34HB and cellulose aerogel was developed. A low-cost aqueous solution of $7 \mathrm{wt} \%$ $\mathrm{NaOH} / 12$ wt\% urea was used as cellulose solvent. After regenerating by $\mathrm{Na}_{2} \mathrm{SO}_{4}$ solution, porous cellulose aerogel was prepared by freeze-drying. The biocomposite from P34HB and cellulose aerogel was developed by the immersion and hot-pressing process. The morphology, crystallization, thermal, mechanical, and barrier properties $\left(\mathrm{H}_{2} \mathrm{O}\right)$ of biocomposite were investigated. The biocomposite from P34HB and cellulose aerogel not only can broaden the use of cellulose in renewable biological resources, but also it can replace some of the traditional petrochemical materials in the packaging field.

\section{EXPERIMENTAL}

\section{Materials}

P34HB containing 12wt\% 4-hydroxybutyrate was a gift from Tianjin Green Bio Material Co., Ltd. (Tianjin, China). Native cellulose from cotton fiber with a degree of polymerization of 475 , a viscosity of $8.25 \mathrm{mPa} \cdot \mathrm{s}$, and a whiteness of 79 points, was purchased from Qingdao Liyuan Dade International Trade Co., Ltd. (Qingdao, China). Other reagents and solvents (analytical reagent) were available on the market and were used when received.

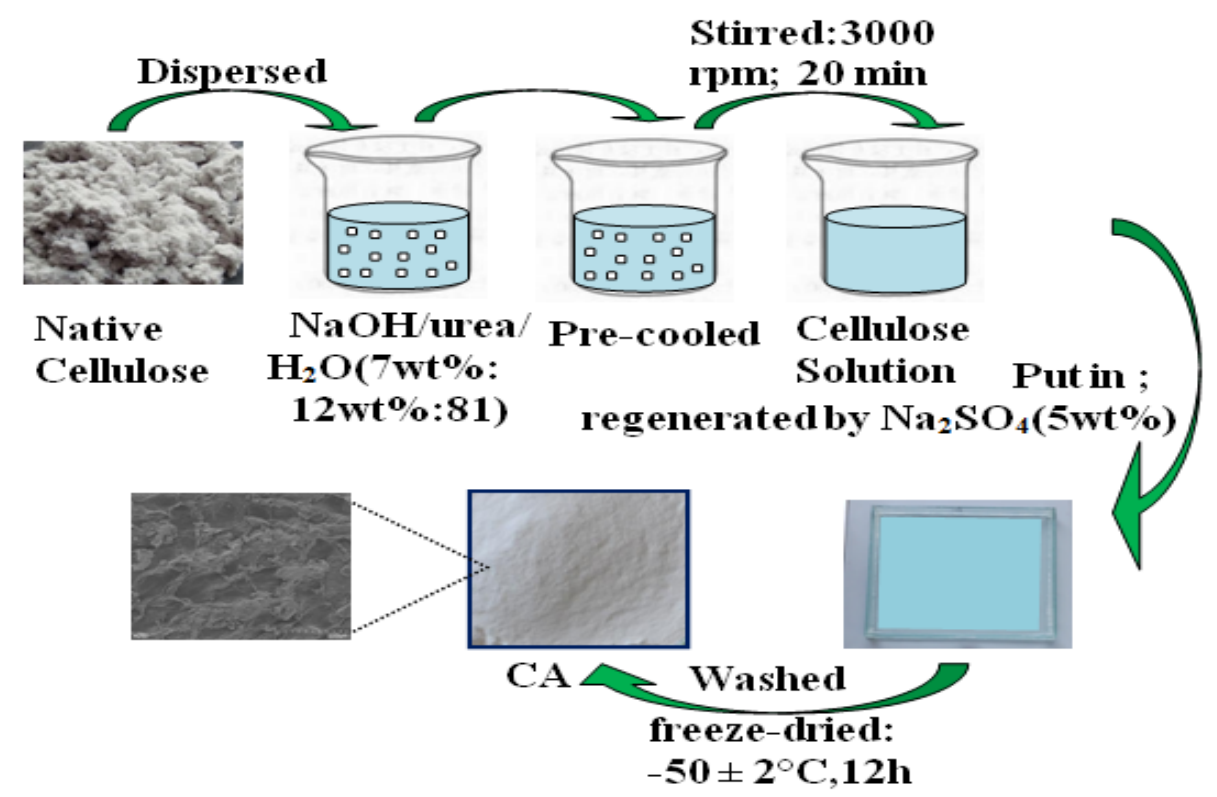

Fig. 1. Schematic of production process of CA 


\section{Preparation of the Cellulose Aerogel Films}

Native cellulose was dispersed into an aqueous $\mathrm{NaOH} /$ urea solution $(7$ wt\%/12 $\mathrm{wt} \%$ ) and then placed at $-20{ }^{\circ} \mathrm{C}$ for $0.5 \mathrm{~h}$. After freezing, the solution was stirred at 3000 rpm for $20 \mathrm{~min}$ to form a transparent cellulose solution $(3.5 \mathrm{wt} \%)$. The obtained solution (containing $0.8 \mathrm{~g}$ cellulose) was placed in glass molds $(100 \mathrm{~mm} \times 100 \mathrm{~mm} \times 4 \mathrm{~mm})$ and regenerated by $\mathrm{Na}_{2} \mathrm{SO}_{4}$ solution $(5 \mathrm{wt} \%)$. The cellulose hydrogel films were washed and freeze-dried at $-50 \pm 2^{\circ} \mathrm{C}$ for at least $12 \mathrm{~h}$ (Jiménezsaelices et al. 2017). The cellulose aerogel films (CA) were obtained. The production process is shown in Fig. 1.

\section{Preparation of P34HB/Cellulose Aerogel Biocomposites}

The cellulose aerogel films were immersed into $50 \mathrm{~mL}$ of $\mathrm{P} 34 \mathrm{HB}$ dichloromethane solution and then vacuum-dried at $60{ }^{\circ} \mathrm{C}$ for $48 \mathrm{~h}$ to obtain the P34HB/cellulose aerogel biocomposites. Different P34HB contents of 10\%, 20\%, 30\%, and $40 \%$ (mass fraction) were used to prepare the biocomposite films on the dry basis. The samples were denoted as 10\%P34HB-CA, 20\%P34HB-CA, 30\%P34HB-CA, and 40\%P34HB-CA, named P34HB-90CA, P34HB-80CA, P34HB-70CA, and P34HB60CA, respectively. Finally, the obtained biocomposites were hot pressed (Automatic hot press; model 4533, Carver, Culver City, CA, USA) under $490 \mathrm{MPa}$ and $103{ }^{\circ} \mathrm{C}$ for $5 \mathrm{~min}$.

\section{Characterization}

A scanning electron microscope (SEM; model SU1510, Hitachi, Tokyo, Japan) with an acceleration voltage of $5 \mathrm{kV}$ was used to analyze the surface and cross-section of biocomposites.

Polarized optical microscopy (POM) analysis was carried out using an OLYMPUS BX51 microscope (Tokyo, Japan) equipped with an IMOTO MHS-2000 heating stage. The sample was sandwiched between two glass slides, which were placed onto a hot-stage set at $180^{\circ} \mathrm{C}$ at a heating rate of $5{ }^{\circ} \mathrm{C} \mathrm{min}^{-1}$ and subsequently cooled to room temperature. The morphologies of the spherulites were recorded by micrograph software.

A Nicolet 6700 FTIR (Thermo Electron, Waltham, MA, USA) was adopted to measure the samples with a resolution of $16 \mathrm{~cm}^{-1}$, so as to obtain IR spectrum diagrams using the $\mathrm{KBr}$ disc technique.

The surface area and the porosity of the samples were determined by $\mathrm{N}_{2}$ adsorption-desorption isotherms measured at $77 \mathrm{~K}$ in a Micromeritics ASAP-2020 apparatus (Norcross, GA, USA). Before $\mathrm{N}_{2}$ adsorption, the samples were degassed at 80 ${ }^{\circ} \mathrm{C}$ for $12 \mathrm{~h}$. Pore size distributions were calculated using the density functional theory (DFT) Plus Soft-ware (provided by Micromeritics), which is based on calculated adsorption isotherms for pores of different sizes.

Thermal stability of the composite films was evaluated using a thermogravimetric analyzer (TGA 209, Netzsch Instruments, Bavaria, Germany). Approximately $5 \mathrm{mg}$ of each film sample was taken in a standard aluminum pan and heated from 30 to $600{ }^{\circ} \mathrm{C}$ at a heating rate of $10{ }^{\circ} \mathrm{C} \mathrm{min}-1$ in a dynamic nitrogen atmosphere.

Thermal properties of the samples were evaluated by DSC using a Netzsch DSC 204F1 Phoenix thermal analysis system (Bavaria, Germany). The sample treatment consisted of a first heating step from $0{ }^{\circ} \mathrm{C}$ to $180{ }^{\circ} \mathrm{C}$, a subsequent cooling to $-50^{\circ} \mathrm{C}$, and a second heating step to $180{ }^{\circ} \mathrm{C}$ at the heating rate of $10{ }^{\circ} \mathrm{C} \mathrm{min}{ }^{-1}$. The cooling rates for the runs were also $10{ }^{\circ} \mathrm{C} \mathrm{min}^{-1}$. All experiments were performed under a nitrogen atmosphere with the nitrogen flow rate of $50 \mathrm{~mL} \mathrm{~min}^{-1}$. 
Mechanical properties of film samples were measured using an Instron universal testing machine (model 3369, Boston, USA) according to the ASTM D 882-10 (2010). The machine was operated with an initial grip separation of $50 \mathrm{~mm}$ and a crosshead speed of $50 \mathrm{~mm} \mathrm{~min}$. Tensile strength and elongation at break were measured. Five replicates were tested for each film sample, and the average values were presented.

Water contact angle was measured at $23 \pm 2{ }^{\circ} \mathrm{C}$ and ambient relative humidity (RH; ca. 60\%) in a digital microscope contact angle tester (VCA Optima, American Stress Technologies Inc., Pittsburgh, PA, USA). Contact angle measurements were achieved by analyzing the shape of a distilled water drop $(2 \mathrm{~mL})$ placed on the film for 12 s.

The water vapor permeability (WVP) was measured using a W3/031 vaporpermeability tester (Ji'nan Languang Electromechanical Technology Co., Ltd., Ji'nan, China). The test temperature was $23{ }^{\circ} \mathrm{C}$, and three replicates were carried out for each material.

\section{RESULTS AND DISCUSSION}

\section{Pore Structure of Cellulose Aerogel Film}

The $\mathrm{N}_{2}$ adsorption/desorption isotherms and pore size distribution of CA are shown in Fig. 2. The isotherms of CA displayed type III according to the IUPAC classification (Fig. 2(a)). The CA pore width was between 4 and $20 \mathrm{~nm}$ (Fig. 2(b)). Therefore, it was believed that the wider pore distribution would be very advantageous for the impregnation of P34HB.
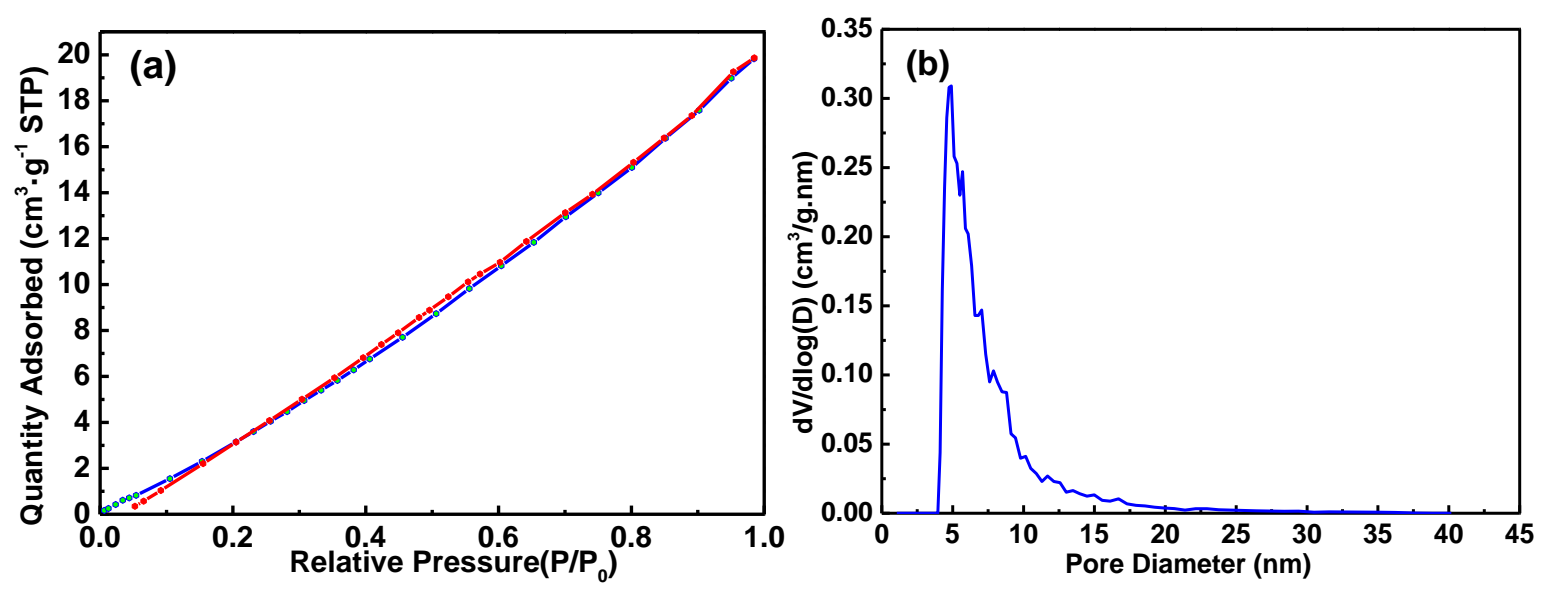

Fig. 2. Adsorption isothermal curve and pore size distributions of CA: (a) Adsorption isothermal curve, (b) Pore size distributions (DFT method)

\section{Morphological Characteristics}

Figure 3 shows the SEM micrographs of P34HB/cellulose aerogel biocomposites. The cross-section of CA had a high porous structure consisting of a three-dimensional network after freeze-drying the cellulose aerogel film (Fig. 3(a)), but the threedimensional network structure collapsed due to hot pressing. The cross-section of P34HB/cellulose aerogel biocomposites became smoother with increased P34HB content. Moreover, the pore structure of biocomposites gradually reduced due to the filled P34HB. This observation agrees with the surface of biocomposites (the inset images of Fig. 3). 

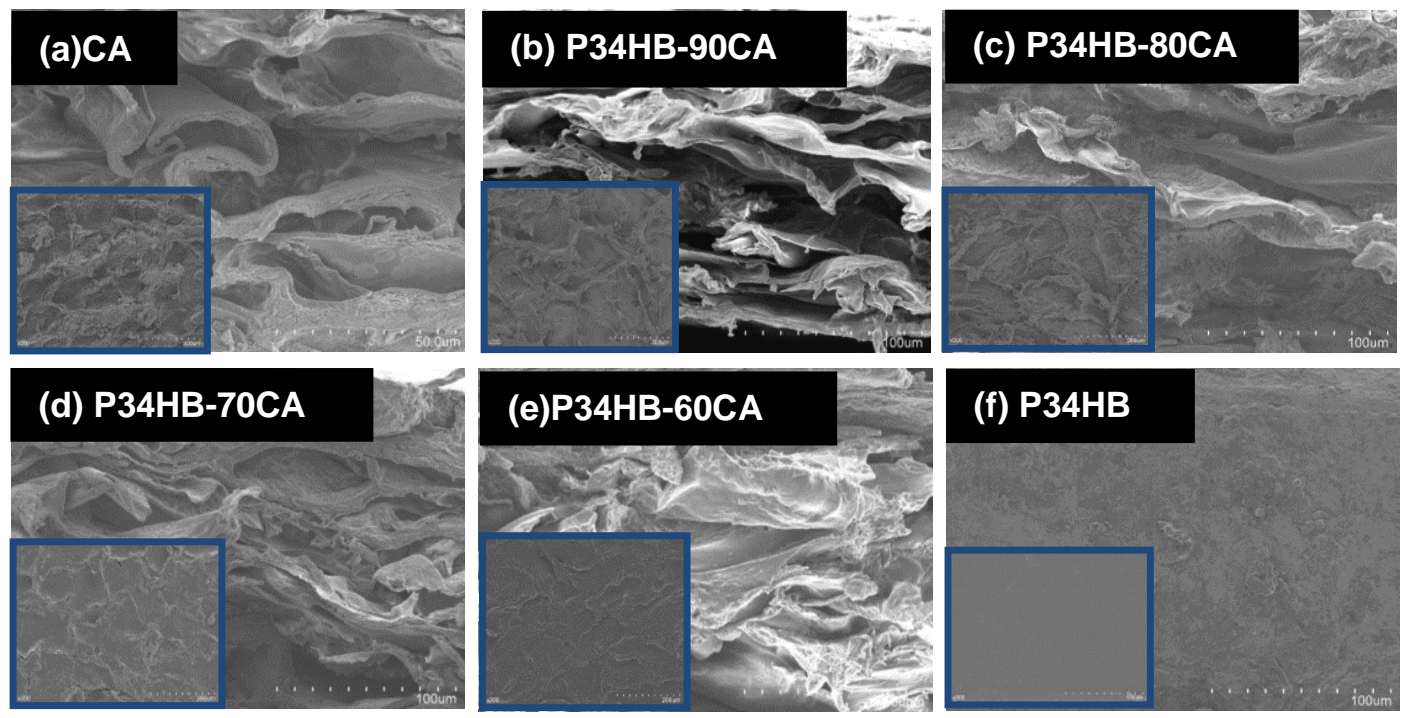

Fig. 3. SEM images of $\mathrm{P} 34 \mathrm{HB} /$ cellulose aerogel biocomposites

\section{Crystallization Behavior}

The crystallization behaviors of $\mathrm{P} 34 \mathrm{HB}$ were also investigated by polarized optical microscopy (Fig. 4). In neat P34HB, the typical spherulite morphology with "Maltese Cross" extinction pattern was observed, and those spherulites exhibit concentric extinction bands in POM (Fig. 4(a)). A polarized micrograph of the P34HB/cellulose aerogel biocomposites at $180{ }^{\circ} \mathrm{C}$ was not bright due to the fibrous structure (Fig. 4b-c). In addition, the network structure of cellulose gradually appeared with the increase of cellulose aerogel. As a result, the network structure of aerogels destroyed the crystal structure of composites and changed the crystallization behavior of $\mathrm{P} 34 \mathrm{HB}$ in composites.
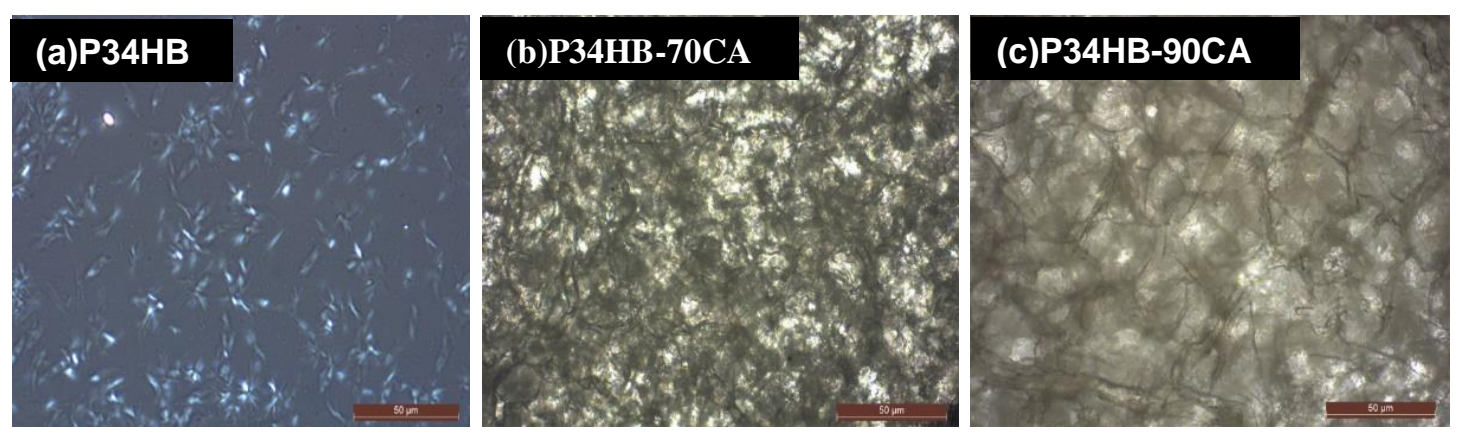

Fig. 4. $\mathrm{POM}$ images of $\mathrm{P} 34 \mathrm{HB} /$ cellulose aerogel biocomposites

\section{FT-IR Analysis}

The FT-IR spectra of P34HB, CA, and P34HB/cellulose aerogel biocomposites are shown in Fig. 5. All of the characteristic peaks of P34HB and CA appeared in the FTIR spectra of biocomposites. With the increasing mass fraction of $\mathrm{P} 34 \mathrm{HB}$, the peak intensity around 1376 and $1720 \mathrm{~cm}^{-1}$ representing methyl stretching vibrations modes of methyl and $\mathrm{C}=\mathrm{O}$ stretching vibration of ester of $\mathrm{P} 34 \mathrm{HB}$ was strengthened gradually (Che et al. 2018). The band at $2914 \mathrm{~cm}^{-1}$ representing stretching vibration of $\mathrm{C}-\mathrm{H}$ of cellulose was gradually weakened. In addition, broad and strong bands near $3400 \mathrm{~cm}^{-1}$ were observed, which represented the superposition of the stretching vibration of hydroxyl 
groups $(\mathrm{OH})$ in the cellulose molecule. With the increasing mass fraction of $\mathrm{P} 34 \mathrm{HB}$, the superposition area of the stretching vibration of hydroxyl groups $(\mathrm{OH})$ increased, indicating decreased hydrophilic properties of the biocomposites.

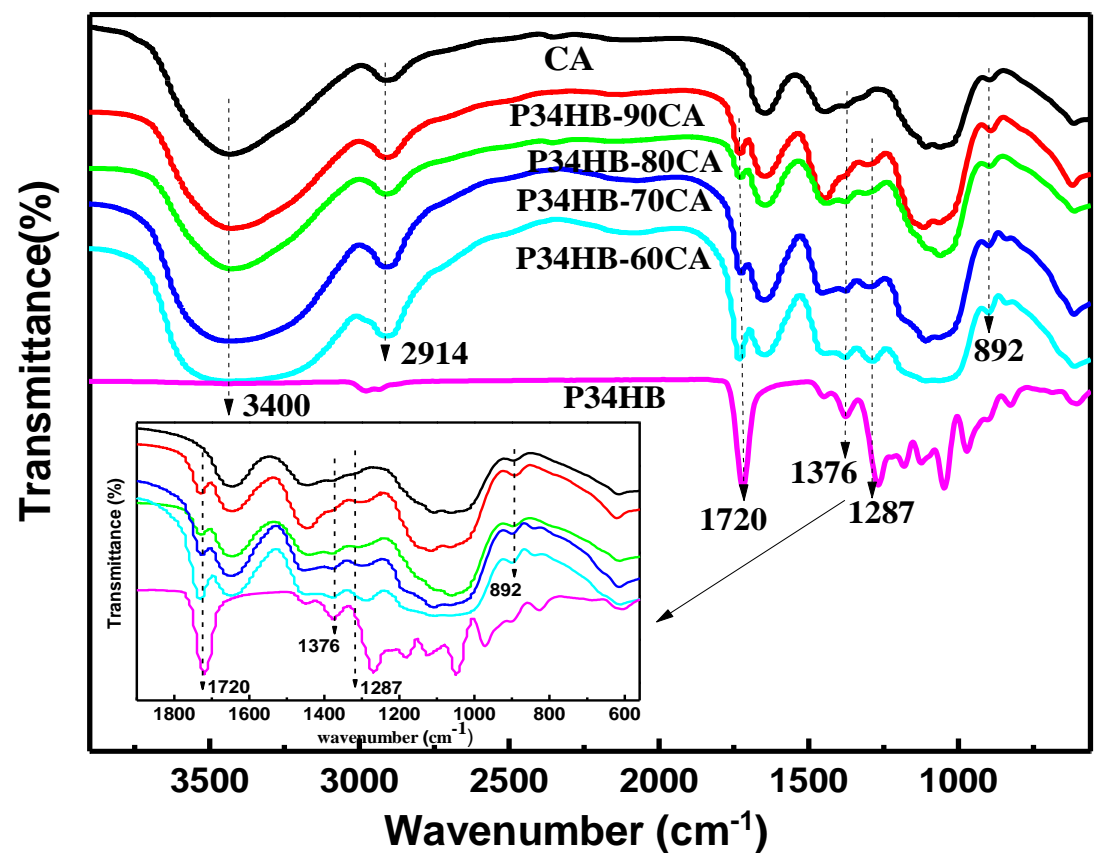

Fig. 5. FT-IR spectra of P34HB/cellulose aerogel biocomposites

\section{Thermal Characterization}

Figure 6 shows the typical TGA and DTG curves of P34HB, CA, and P34HB /cellulose aerogel biocomposites.
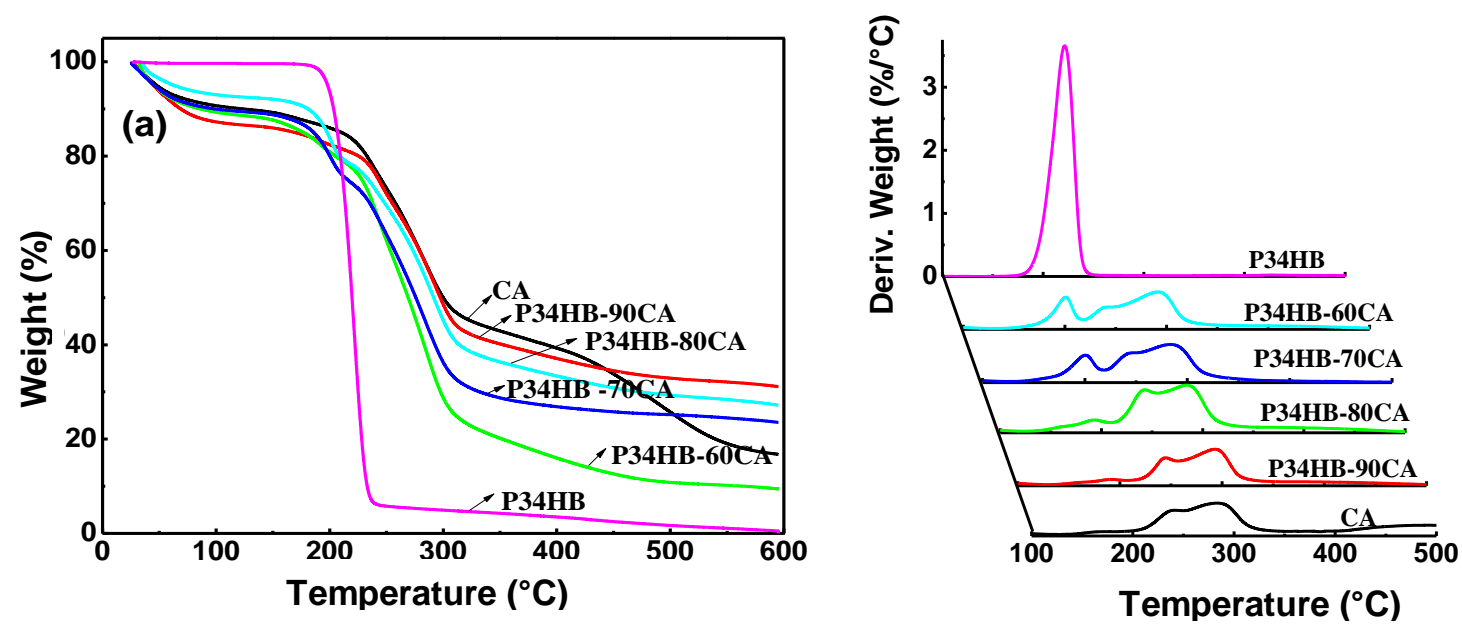

Fig. 6. Thermal properties of P34HB/cellulose aerogel biocomposites: (a) TGA curves, (b) DTG curves

Figure 6(a) shows that the P34HB had good thermal degradation through a onestep process, and $\mathrm{P} 34 \mathrm{HB}$ was thermally stable up to $221{ }^{\circ} \mathrm{C}$ with almost no mass loss. The TGA curves of CA and P34HB/cellulose aerogel biocomposites showed stepwise degradation behaviors. The curves from room temperature to $218{ }^{\circ} \mathrm{C}$ were relatively flat, 
and the loss of mass resulted from evaporation of water before $\mathrm{P} 34 \mathrm{HB}$ and CA began to break down. The mass loss near $197{ }^{\circ} \mathrm{C}$ to $295{ }^{\circ} \mathrm{C}$ was due to the thermal depolymerization of the hemicellulose, the destruction of the crystallization zone, and thermal degradation of P34HB (Hosoda et al. 2014). The mass loss near $295{ }^{\circ} \mathrm{C}$ to 395 ${ }^{\circ} \mathrm{C}$ was the decomposition of cellulose. The decomposition temperature of the P34HB/cellulose aerogel biocomposites was shown in the DTG diagram (Fig. 6(b)). With increased $\mathrm{P} 34 \mathrm{HB}$ content, the first decomposition temperature and second decomposition temperature gradually shifted to the high temperature, which indicated that the thermal degradation temperature of the composite films increased, and the thermal stability of the composite films was enhanced (Ventura et al. 2017).

Thermal properties of the $\mathrm{P} 34 \mathrm{HB}, \mathrm{CA}$, and $\mathrm{P} 34 \mathrm{HB} /$ cellulose aerogel biocomposites were investigated by DSC analyses. The second heating DSC thermogram is illustrated in Fig. 7. The glass transition temperature of $\mathrm{P} 34 \mathrm{HB} /$ cellulose aerogel biocomposites was hardly changed. Similar results were reported in previous studies (Liu et al. 2010; Bojda and Piorkowska 2016; Jape and Deshpande 2017). The cold crystallization temperature was about $80{ }^{\circ} \mathrm{C}$. With the increase of P34HB content, the cold crystallization temperature tended to shift to low temperature. This behavior was because the increase of $\mathrm{P} 34 \mathrm{HB}$ affected the rearrangement of molecular chains when the melt matrix changed from melt state to crystalline state, which decreased the crystallinity of the mixture and the cold crystallization temperature. With the increase of P34HB content, the melting temperature increased gradually, contributing to form a small critical nucleus of P34HB because of the three-dimensional network structure of cellulose (Gonzalez-Ausejo et al. 2017). However, when P34HB content was increased to $40 \mathrm{wt} \%$, the melting temperature decreased. This might be due to the inhibition of the threedimensional network structure of cellulose on a large number of $\mathrm{P} 34 \mathrm{HB}$ chain pairs.

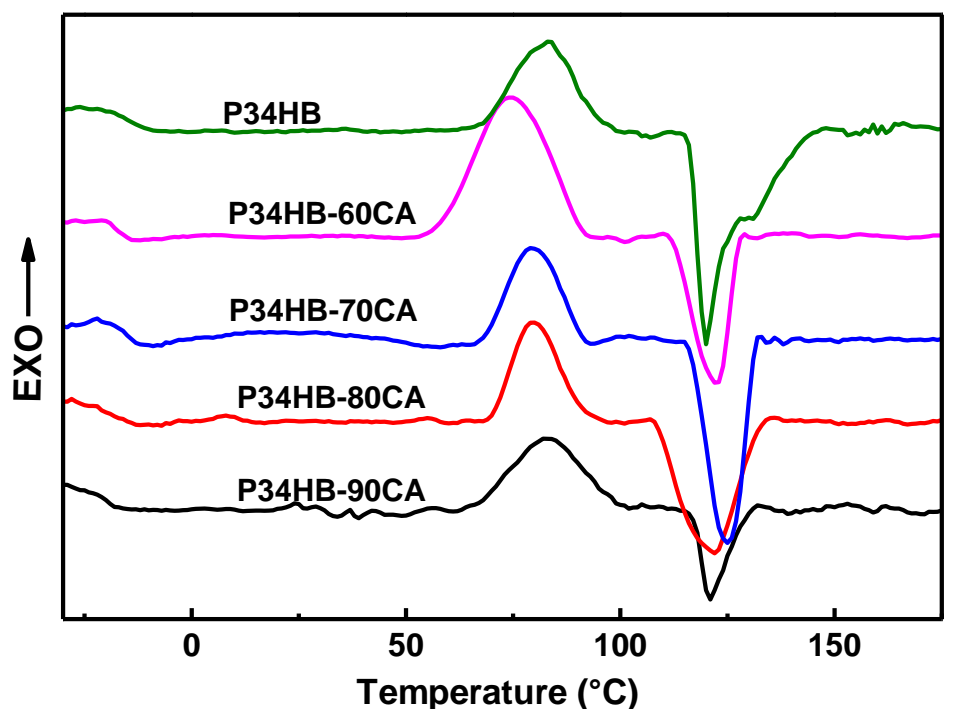

Fig. 7. The DSC curves of P34HB/cellulose aerogel biocomposites

\section{Mechanical Properties}

Figure 8 shows the stress-strain curves, the tensile strength, elongation at break, and elastic modulus of biocomposites. From the stress-strain curve, it can be seen that the fracture of all samples was brittle fracture, and the fracture strain of the stress-strain curve first increased and then decreased as P34HB content increased. Tensile strength 
and elongation at break had the same trend as fracture strain. With $30 \mathrm{wt} \% \mathrm{P} 34 \mathrm{HB}$, biocomposites exhibited the best mechanical properties, corresponding to $5.09 \mathrm{MPa}$ of tensile strength and $6.82 \%$ of tensile elongation at break, which was $48 \%$ and $25.1 \%$ higher, respectively, than the values for CA. This result suggests that $\mathrm{CA}$ and $\mathrm{P} 34 \mathrm{HB}$ increased the interfacial bonding force when they were hot pressed, thus achieving the effect of P34HB enhancement. The mechanical property of P34HB-60CA decreased. The reason was that the incompatibility of cellulose aerogels and $\mathrm{P} 34 \mathrm{HB}$ increased with the high $\mathrm{P} 34 \mathrm{HB}$ content, resulting in the limited interface bonding by hot pressing. The mechanical properties of $\mathrm{P} 34 \mathrm{HB} /$ cellulose aerogel biocomposites were not greatly improved. The porous cellulose aerogel film was immersed into P34HB dichloromethane solution, and the pores in cellulose aerogel films were filled by P34HB. Thus, P34HB was divided between cellulose aerogel, leading to no strong hydrogen bonding between cellulose molecules and P34HB molecules, which was consistent with the results of FTIR.
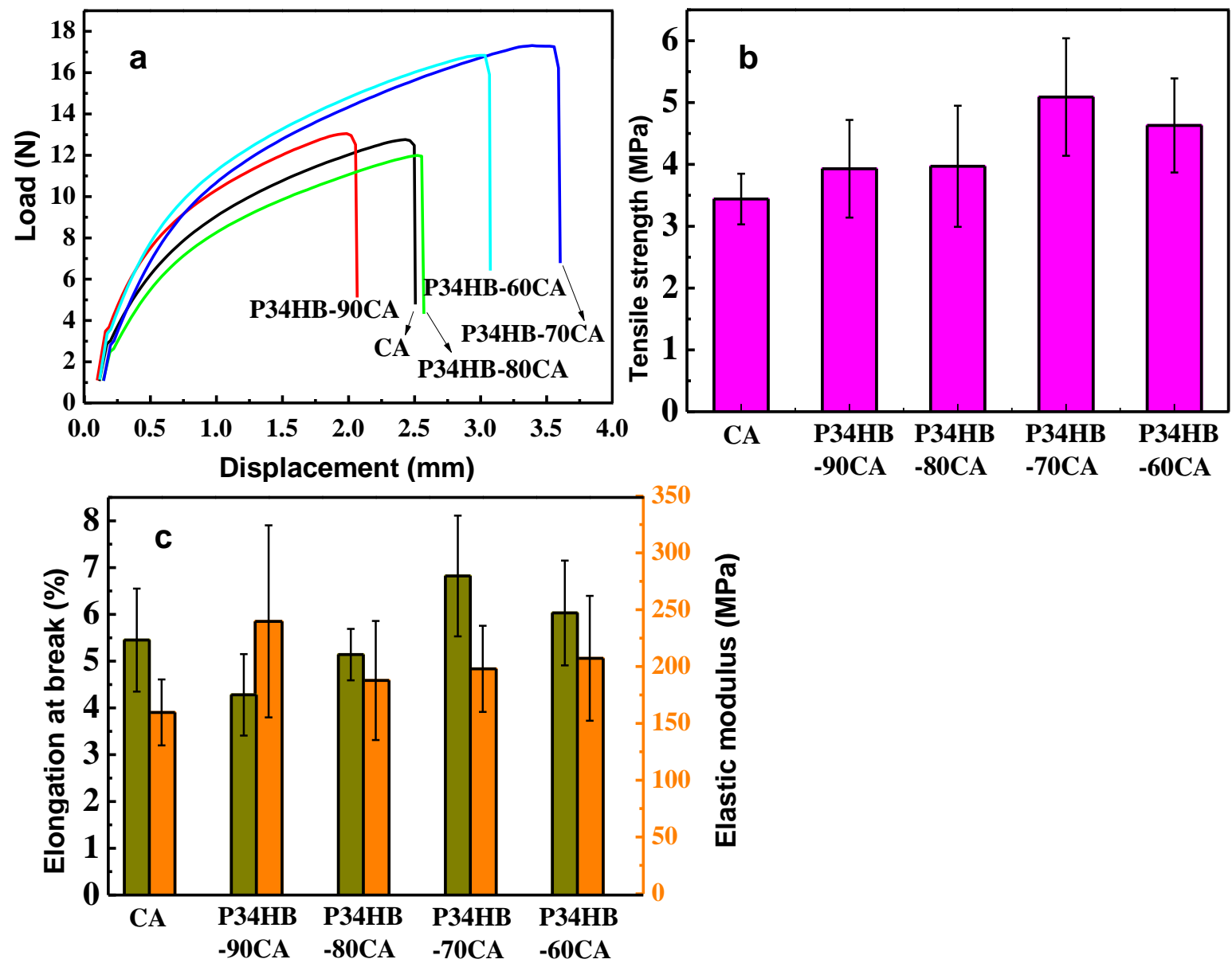

Fig. 8. Mechanical properties of P34HB/cellulose aerogel biocomposites: (a) Stress-strain curve, (b) Tensile strength, (c) Elongation at break and elastic modulus

\section{Wettability and Barrier Properties}

The Wenzel state of contact angle indicates that the hydrophobicity and roughness of the film surface greatly influences the contact angle (Mohammad et al. 2017). Figure 
9(a) shows the change of contact angle of CA and biocomposites. The contact angle between water droplets and the biocomposites surface decreased gradually with the increase of time, and the reduction rate of contact angle diminished when the P34HB content increased, indicating that the surface of biocomposites was more smooth after hot pressing. The contact angle of the cellulose film was small, which is because the cellulose itself contains a large number of hydrophilic hydroxyl groups, making cellulose aerogel more hydrophilic. With the increase of P34HB content, the contact angle between water droplet and biocomposites increased, implying that more cellulosic aerogel pores were filled by P34HB.

Water vapor permeability (WVP) curves of CA and P34HB/cellulose aerogel biocomposites are presented in Fig. 9(b). The permeation decreased with the increased P34HB content owing to the hydrophobicity of the polymer (Seoane et al. 2015; Cyras et al. 2007). The WVP of cellulose aerogel was maximum due to the hydroxyl groups, which showed hydrophilicity and strong hygroscopic property. With the increase of $\mathrm{P} 34 \mathrm{HB}$ content, the WVP of $\mathrm{P} 34 \mathrm{HB} /$ cellulose aerogel biocomposites showed a decreasing trend. This was attributed to there being more pores in cellulose films filled by $\mathrm{P} 34 \mathrm{HB}$ with increasing of $\mathrm{P} 34 \mathrm{HB}$ content, and the $\mathrm{P} 34 \mathrm{HB}$ chain was hydrophobic, contributing to a tortuous path for the diffusion of water vapor through the polymer matrix (Shankar et al. 2017). This result is important because lower WVP values indicate better moisture protection to the packaged food. Therefore, in the storage process, due to the reduction of moisture through packaging, food deterioration may be reduced (Correa et al. 2017). Furthermore, the interfacial adhesion between cellulose and P34HB increased after hot pressing.
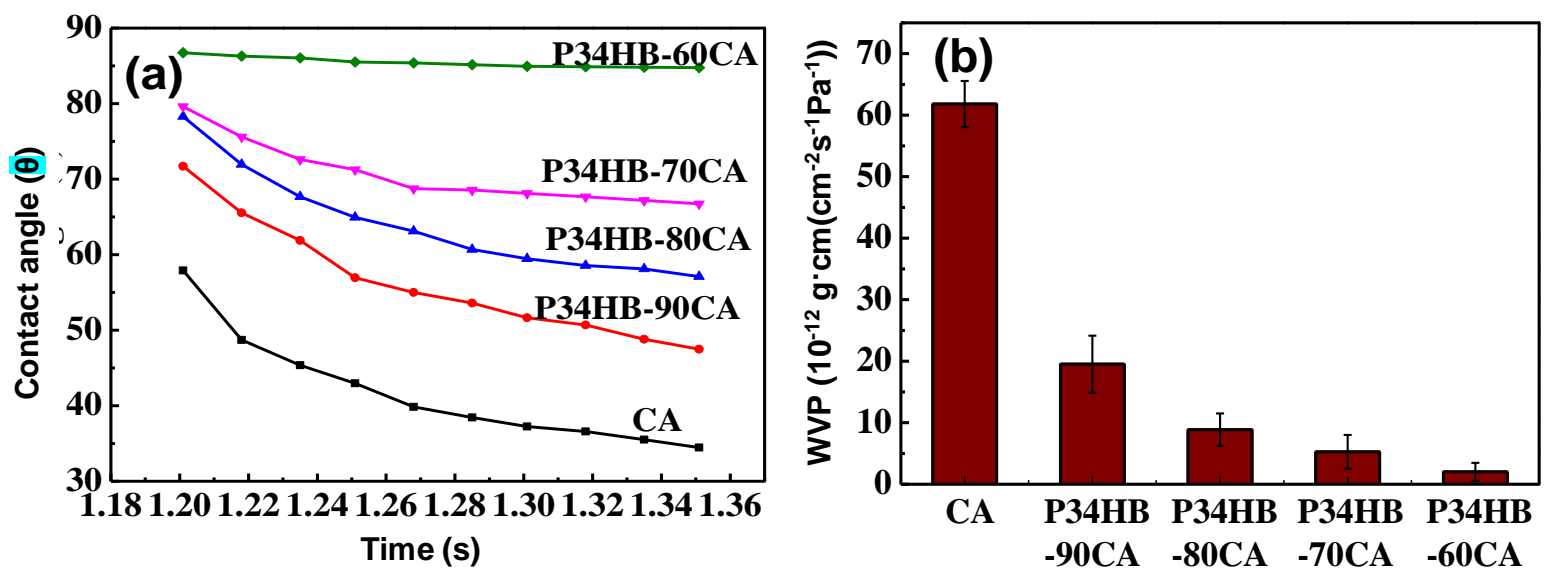

Fig. 9. The change of contact angle (a) and water vapor transmission rate curves (b) of P34HB/cellulose aerogel biocomposites

\section{CONCLUSIONS}

1. A novel green biocomposite from poly(3-hydroxybutyrate-co-4-hydroxybutyrate) $(\mathrm{P} 34 \mathrm{HB})$ and cellulose aerogel was developed by the immersion and hot-pressing process.

2. The pore structure and morphology of cellulose aerogels revealed that cellulose aerogel exhibited a three-dimensional network structure with porosity and wider pore 
distribution. This structure contributed to the change of the glass transition temperature and cold crystallization temperature of $\mathrm{P} 34 \mathrm{HB} /$ cellulose aerogel biocomposites.

3. With the increase of P34HB content, the tensile strength and elongation at break of the P34HB/cellulose aerogel biocomposites first increased and then decreased.

4. Biocomposites demonstrated increased contact angle and decreased water vapor permeability (WVP) compared with the cellulose aerogel. The results highlighted the potential of $\mathrm{P} 34 \mathrm{HB} /$ cellulose aerogel biocomposites for practical application as a packaging material.

\section{ACKNOWLEDGMENTS}

This work was financially supported by the Tianjin Natural Science Foundation (18JCYBJC90100).

\section{REFERENCES CITED}

Bojda, J., and Piorkowska, E. (2016). "Shear-induced nonisothermal crystallization of two grades of PLA," Polym. Test. 50, 172-181. DOI:

10.1016/j.polymertesting.2016.01.006

Bo, S. G., Ren, W. J., Lei, C., Xie, Y. B., Cai, Y. R., Wang, S. L., Gao, J. K., Ni, Q. Q., and Yao, J. M. (2018). "Flexible and porous cellulose aerogels/zeolitic imidazolate framework (ZIF-8) hybrids for adsorption removal of Cr(IV) from water," J. Solid State Chem. 262, 135-141. DOI: 10.1016/j.jssc.2018.02.022

Cyras, V. P., Commisso, M. S., Mauri, A. N., and Vázquez, A. (2007). "Biodegradable double-layer films based on biological resources: Polyhydroxybutyrate and cellulose," J. Appl. Polym. Sci. 106, 749-756. DOI: 10.1002/app.26663

Cai, Z., Jia, J., Zhang, Q., Zhao, S., and Guo, J. (2016). "Preparation and characterization of novel poly(3-hydroxybutyrate-co-4-hydroxybutyrate)/cellulose acetate composite fibers," Mater. Lett. 173, 119-122. DOI: 10.1016/j.matlet.2016.03.019

Chiulan, I., Mihaela Panaitescu, D., Nicoleta Frone, A., Teodorescu, M., Andi Nicolae, C., Căşărică, A., Tofan, V., and Sălăgeanu, A. (2016). "Biocompatible polyhydroxyalkanoates/bacterial cellulose composites: Preparation, characterization, andin vitroevaluation," J. Biomed Mater. Res. A 104, 2576-2584.

DOI:10.1002/jbm.a.35800

Cherpinski, A., Torres-Giner, S., Vartiainen, J., Peresin, M. S., Lahtinen, P., and Lagaron, J. M. (2018). "Improving the water resistance of nanocellulose-based films with polyhydroxyalkanoates processed by the electrospinning coating technique," Cellulose 25, 1291-1307. DOI: 10.1007/s10570-018-1648-z

Che, X. M., Ye, H. M., and Chen, G. Q. (2018). "Effects of uracil on crystallization and rheological property of poly(R-3-hydroxybutyrate-co -4-hydroxybutyrate)," Compos. Part A- Appl. S 109, 141-150. DOI: 10.1016/j.compositesa.2018.03.006

Chen, J., Guan, Y., Wang, K., Zhang, X., Xu, F., and Sun, R. (2015). "Combined effects of raw materials and solvent systems on the preparation and properties of regenerated cellulose fibers," Carbohyd. Polym. 128, 147-153. DOI: 


\subsection{6/j.carbpol.2015.04.027}

Du, M., Du, Y., Feng, Y., Yang, K., Lv, X., Jiang, N., and Liu, Y. (2018). "Facile preparation of biobr/cellulose composites by in situ synthesis and its enhanced photocatalytic activity under visible-light," Carbohyd. Polym. 195, 393-400. DOI: 10.1016/j.carbpol.2018.04.092

Gonzalez-Ausejo, J., Rydz, J., Musioł, M., Sikorska, W., Sobota, M., Włodarczyk, J., Shankar, S., Wang, L. F., and Rhim, J. W. (2017). "Preparation and properties of carbohydrate-based composite films incorporated with $\mathrm{CuO}$ nanoparticles," Carbohyd. Polym. 169, 264-271. DOI: 10.1016/j.carbpol.2017.04.025

Guo, L., Chen, Z., Lyu, S., Fu, F., and Wang, S. (2017). "Highly flexible cross-linked cellulose nanofibril sponge-like aerogels with improved mechanical property and enhanced flame retardancy," Carbohyd. Polym. 179, 333-340. DOI: 10.1016/j.carbpol.2017.09.084

Guo, T. Y., Song, J. L., Jin Y. C., Sun, Z. H., and Li, L. (2018). “Thermally stable and green cellulose-based composites strengthened by styrene-co-acrylate latex for lithium-ion battery separators," Carbohyd. Polym. 206, 801-810. DOI: 10.1016/j.carbpol.2018.11.025

Hosoda, N., Tsujimoto, T., and Uyama, H. (2014). "Green composite of poly(3hydroxybutyrate- co-3-hydroxyhexanoate) reinforced with porous cellulose," ACS Sustainable Chem. Eng. 2, 248-253. DOI: 10.1021/sc400290y

Jape, S. P., and Deshpande, V. D. (2017). "Nonisothermal crystallization kinetics of nylon 66/LCP blends," Thermochim Acta 655, 1-12. DOI: 10.1016/j.tca.2017.06.007

Jiménezsaelices, C., Seantier, B., Cathala, B., and Grohens, Y. (2017). "Spray freezedried nanofibrillated cellulose aerogels with thermal superinsulating properties," Carbohyd. Polym. 157, 105-113. DOI: 10.1016/j.carbpol.2016.09.068

Larsson, M., Hetherington, C. J. D., Wallenberg, R., and Jannasch, P. (2017). "Effect of hydrophobically modified graphene oxide on the properties of poly(3-hydroxybutyrate-co-4-hydroxybutyrate)," Polymer 108, 66-77. DOI:

10.1016/j.polymer.2016.11.042

Liu, H. X., Huang, Y. Y., Yuan, L. A., He, P. S., Cai, Z. H., Shen, Y. L., Xu, Y. M., Yu, Y., and Xiong, H. G. (2010). "Isothermal crystallization kinetics of modified bamboo cellulose/PCL composites," Carbohyd. Polym. 79, 513-519. DOI:

10.1016/j.carbpol.2009.08.037

Mohammad, K. A., Rothstein, J. P., and Kavehpour, H. P. (2017). "Experimental study of dynamic contact angles on rough hydrophobic surfaces," J. Colloid Interf. Sci. 513, 658-665. DOI: 10.1016/j.jcis.2017.11.075

Seoane, I. T., Manfredi, L. B., and Cyras, V. P. (2015). "Properties and processing relationship of polyhydroxybutyrate and cellulose biocomposites," Procedia Materials Science 8, 807-813. DOI: 10.1016/j.mspro.2015.04.139

Shankar, S., Wang, L. F., and Rhim, J. W. (2017). "Preparation and properties of carbohydrate-based composite films incorporated with $\mathrm{CuO}$ nanoparticles," Carbohyd. Polym. 169, 264-271. DOI: 10.1016/j.carbpol.2017.04.025

Ventura, H., Claramunt, J., Rodríguez-Pérez, M. A., and Ardanuy, M. (2017). "Effects of hydrothermal aging on the water uptake and tensile properties of PHB/flax fabric biocomposites," Polym. Degrad. Stabil. 142, 129-138. DOI: 10.1016/j.polymdegradstab.2017.06.003

Wang, X., Zhang, H., Liu, M., and Jia, D. (2017). "Thermal stability of poly(3hydroxybutyrate-co-4-hydroxybutyrate)/modified montmorillonite bio- 
nanocomposites," Polym. Composite 38, 673-681. DOI: 10.1002/pc.23626

Wan, C., and Li, J. (2016). "Graphene oxide/cellulose aerogels nanocomposite: preparation, pyrolysis, and application for electromagnetic interference shielding," Carbohyd. Polym. 150, 172-179. DOI: 10.1016/j.carbpol.2016.05.051

Xu, P., Feng, Y., Ma, P., Chen, Y., Dong, W., and Chen, M. (2017). "Crystallization behaviours of bacterially synthesized poly(hydroxyalkanoate)s in the presence of oxalamide compounds with different configurations," Int. J. Biol. Macromol. 104, 624-630.DOI: 10.1016/j.ijbiomac.2017.06.001

Article submitted: March 19, 2019; Peer review completed: April 12, 2019; Revised version received: April 17, 2019; Accepted: April 18, 2019; Published: April 26, 2019. DOI: $10.15376 /$ biores.14.2.4748-4759 